\title{
Part 5 Transient and final provisions
}

\section{§ 57 Transitional provision}

This ordinance may not be applied to basic services that were contractually agreed prior to its entry into force; insofar the previous regulations shall remain applicable.

\section{$\S 58$ Coming into/Going out of force}

This ordinance shall come into force on the day following its promulgation. The Scale of Fees for Architects and Engineers dated 11 August 2009 (Federal Law Gazette/BGB1. I p. 2732) shall go out of force at the same time. 